\title{
Balkanologie
}

Balkanologie Revue d'études pluridisciplinaires

Vol. VIII, $n^{\circ} 2$ | 2004

Volume VIII Numéro 2

\section{Pulevski (G'org'ija), Slavjano-mak'edanska opšta istorija [Histoire générale slavo-macédonienne]}

Skopje : MANU, 2003, XL + 1060 p.

\section{Bernard Lory}

\section{(2) OpenEdition}

\section{Journals}

Édition électronique

URL : http://journals.openedition.org/balkanologie/2036

DOI : 10.4000/balkanologie.2036

ISSN : 1965-0582

\section{Éditeur}

Association française d'études sur les Balkans (Afebalk)

Édition imprimée

Date de publication : 1 décembre 2004

ISSN : 1279-7952

\section{Référence électronique}

Bernard Lory, «Pulevski (G'org'ija), Slavjano-mak'edanska opšta istorija [Histoire générale slavo-

macédonienne] », Balkanologie [En ligne], Vol. VIII, n² 2 | 2004, mis en ligne le 20 janvier 2010, consulté le 17 décembre 2020. URL : http://journals.openedition.org/balkanologie/2036 ; DOI : https://doi.org/ 10.4000/balkanologie.2036

Ce document a été généré automatiquement le 17 décembre 2020.

(C) Tous droits réservés 


\section{Pulevski (G'org'ija), Slavjano- mak'edanska opšta istorija [Histoire générale slavo-macédonienne]}

Skopje : MANU, 2003, XL + 1060 p.

\section{Bernard Lory}

\section{RÉFÉRENCE}

Pulevski (G'org'ija), Slavjano-mak'edanska opšta istorija [Histoire générale slavomacédonienne], Skopje : MANU, 2003, XL + 1060 p.

1 Une revue comme Balkanologie se devait de saluer la parution d'un ouvrage rare et curieux. Il s'agit en effet du premier ouvrage de balkanologie rédigé en macédonien et resté manuscrit jusqu'à nos jours. Le titre donné à cette édition peut prêter à confusion et laisser entendre qu'il s'agit d'une histoire de la Macédoine; le titre complet est Histoire générale slavo-macédonienne de toutes les nationalités de la Péninsule (Slavjanomak'edonska opšta istorija za svi pol-ostrofski narodnosti) et c'est bien d'une histoire des Balkans qu'il s'agit, couvrant la période du déluge biblique jusqu'en 1892. La Macédoine n'y occupe en fin de compte qu'une place assez modeste.

2 L'auteur, G'org'i Pulevski, est bien connu dans le monde de la linguistique balkanique pour deux lexiques ou manuels de conversation polyglottes, publiés en 1872 et 1875 , qui mettent en parallèle le macédonien, l'albanais, le turc et le grec (sans le grec pour le second). Né en 1817 à Galičnik, en Macédoine occidentale, après une vie aventureuse de maçon, de brigand et de révolutionnaire, il s'adonna à la vulgarisation des connaissances dans ses vieux jours, avec une touchante passion d'autodidacte. Il compila, apparemment en solitaire, cette volumineuse histoire sur la base des ouvrages qu'il avait pu consulter. C'est donc l'œuvre d'un historien-amateur et il ne faut pas en attendre une approche scientifique et critique; elle frappe pourtant par son souci d'ordre et de hiérarchisation de l'information ; l'exposé est en effet haché menu en très 
brefs paragraphes dûment numérotés et regroupés en chapitres, sous-chapitres, parties et sous-parties, successivement annoncés et développés.

3 L'historien de 2004 n'a, il faut bien l'avouer, pas grand chose à y glaner comme information originale, sauf quand Pulevski parle en son propre nom et non pas en compilateur. Il fournit ainsi quelques éclairages intéressants sur les insurrections albanaises des années 1830-1850, lesquelles affectèrent sa région d'origine (pp. 786-789, 799-804). Son survol des sous-ensembles ethnographiques de Bulgarie et de Macédoine et sa perception des différents peuples de la Péninsule n'est pas sans intérêt non plus (pp. 903-921). On peut aussi s'attacher aux choix historiographiques de l'auteur qui sont révélateurs : par exemple son insistance sur Alexandre le Grand (100 pages). Mais en fin de compte, de nos jours, qui va se donner la peine de se frayer une lecture au travers de ces micro-paragraphes, rédigés dans une langue archaïque?

4 L'intérêt de l'ouvrage est en réalité philologique. Il permet de voir comment Pulevski s'efforce de donner à son parler natal de Macédoine occidentale (dialecte mijak) le statut d'une langue scientifique. L'édition du manuscrit réalisée par Blaže Ristovski et Riljana Ristovska-Josifovska est tout à fait exemplaire, par son respect de la graphie de l'auteur (y compris dans ses incohérences) et par la précision des notes de bas de page, indiquant les rectifications opérées ou les lectures possibles. Signalons aussi l'édition sur papier de qualité, reliée, avec annexes scientifiques sur papier rosé... On souhaiterait un traitement aussi respectueux et rigoureux dans toutes les éditions de textes balkaniques!

5 Ce souci louable est révélateur d'une option scientifique propre à la Macédoine (et même plus spécifiquement à l'Académie des Sciences de Macédoine) qu'il est intéressant de relever parce qu'elle constitue une spécificité de la recherche scientifique dans ce pays. Il s'agit d'une sorte de tutelle qu'exercent les études philologiques et littéraires sur la recherche historique. Pour des raisons liées à l'histoire de la langue, une importance considérable est conférée à des auteurs qui n'ont eu, de leur vivant qu'un impact très limité (K. Misirkov, D. Čupovski, par exemple) mais qu'une vision rétrospective de l'histoire macédonienne dans une approche nationale investit d'un rôle majeur. L'histoire de l'idéologie nationale macédonienne est le plus souvent traitée par des linguistes ou des chercheurs en littérature, dont la formation tend à absolutiser l'importance du document écrit (souvent ils parlent de "monuments écrits ») sans prendre suffisamment en compte le contexte de l'époque, les problèmes de diffusion et d'audience. En l'occurrence, si Pulevski écrit bel et bien en macédonien (en "mijak littéraire»), on ne peut pas dire qu'il ait une perception macédonienne de l'histoire des Balkans; s'il contribue à l'affirmation linguistique de la spécificité macédonienne, sa position en tant qu'historien reflète celle des ouvrages de vulgarisation (apparemment russes) qu'il a utilisés. De façon révélatrice, cette édition si minutieuse ne se préoccupe pas de savoir quels ouvrages historiques précis Pulevski a utilisés; il n'a très vraisemblablement pas utilisé directement les sources (grecques, latines, byzantines, etc.) que les éditeurs ont relevées scrupuleusement, mais des ouvrages de seconde main: l'approche philologique laisse l'historien insatisfait. 